\title{
CASE REPORT - ISOLATED APICAL HYPERTROPHIC CARDIOMYOPATHY
}

\author{
Monica $A^{1}$, Prabhu $G^{2}$, Balasubramaniyan $S^{3}$
}

1 Postgraduate, Department of General Medicine, Rajah Muthiah Medical College and Hospital.

${ }^{2}$ Reader, Department of General Medicine, Rajah Muthiah Medical College and Hospital.

${ }^{3} \mathrm{HOD}$ and Chief, Department of General Medicine, Rajah Muthiah Medical College and Hospital.

\begin{abstract}
A rare form of hypertrophic cardiomyopathy predominantly involving the left ventricular apex is called as Apical Hypertrophic Cardiomyopathy (AHCM). This variant, more commonly seen in Japanese populations had been detected in a middle-aged SouthIndian man by 2D echocardiography.
\end{abstract}

\section{KEYWORDS}

Cardiomyopathy, Apical Hypertrophy.

HOW TO CITE THIS ARTICLE: Monica A, Prabhu G, Balasubramaniyan S. Case report - isolated apical hypertrophic cardiomyopathy. J. Evolution Med. Dent. Sci. 2016;5(82):6151-6153, DOI: 10.14260/Jemds/2016/1390

\section{INTRODUCTION}

Apical Hypertrophic Cardiomyopathy (AHCM) is a rare form of Hypertrophic Cardiomyopathy (HCM), which usually involves the apex of the left ventricle and rarely involves the right ventricular apex or both. ${ }^{1}$ This relatively rare variant of HCM, first described in Japan, constituted $13 \%$ to $25 \%$ of all cases of HCM in Japan²; however, it is seen much less often in nonJapanese populations. ${ }^{3}$

\section{CASE REPORT}

A 55-year-old South-Indian male, a chronic smoker with a history of systemic hypertension presented with complaints of an acute onset chest pain which was left-sided, intermittent, dull aching with no radiation. History of associated profuse sweating present. He had no complaints of dyspnoea, palpitations, syncope or haemoptysis. There was no family history of sudden cardiac death, congestive heart failure or cardiomyopathy. On examination his blood pressure was $160 / 100 \mathrm{mmHg}$, heart rate was $78 \mathrm{bpm}$ with no heart murmur or any signs of congestive heart failure. Other systemic examination was unremarkable. A 12-lead electrocardiogram (ECG) showed left ventricular hypertrophy and inverted Twaves in I, II, aVL, aVF, V2-V6 (Figure 2). The cardiac enzymes and chest $\mathrm{X}$-ray were normal. A Transthoracic Echocardiogram (TTE) showed apical hypertrophy with adequate LV systolic function and no evidence of regional wall motion abnormality (Figure 1).

Financial or Other, Competing Interest: None.

Submission 01-09-2016, Peer Review 01-10-2016,

Acceptance 06-10-2016, Published 13-10-2016.

Corresponding Author:

Monica A,

234, Lal Bahadur Sastry Street,

Pondicherry-605001.

E-mail: drmonicaanand5@gmail.com

DOI: $10.14260 /$ jemds $/ 2016 / 1390$

(C) $(1) \Theta$

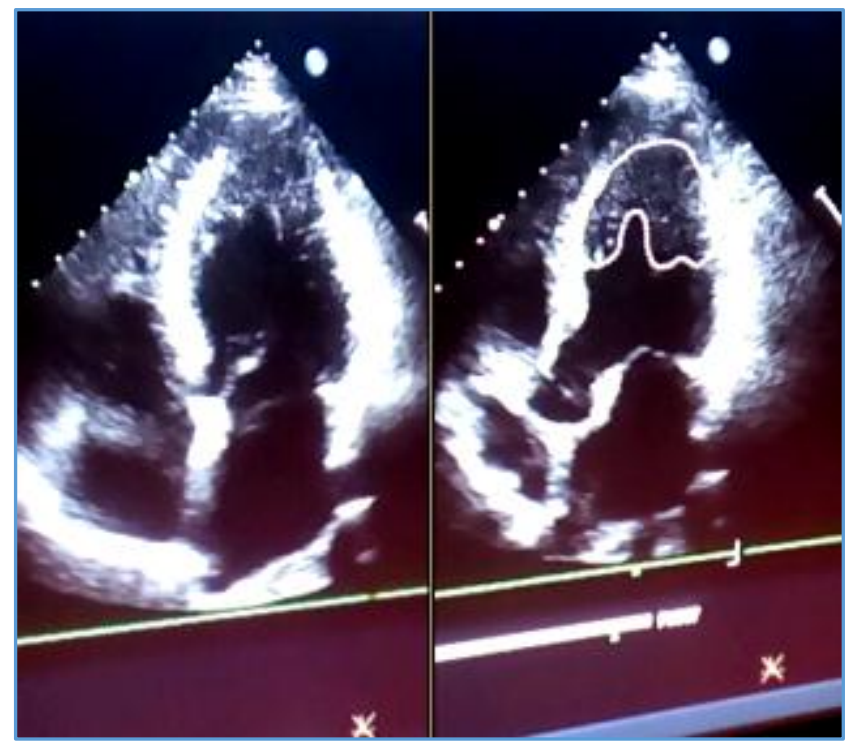

Fig. 1
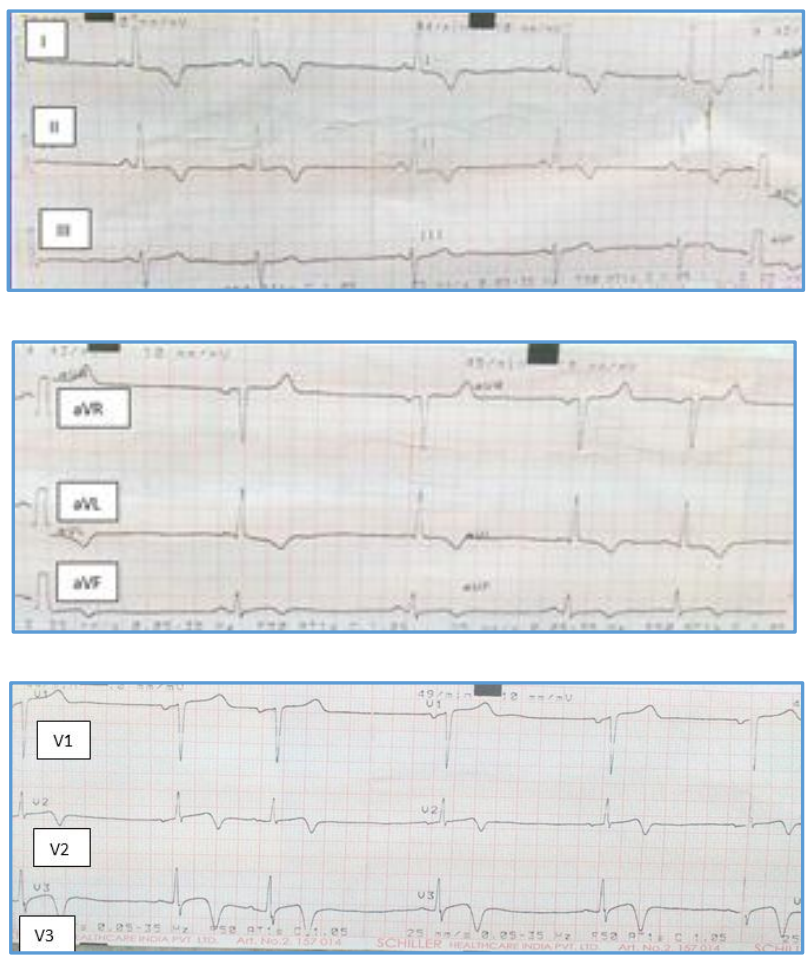


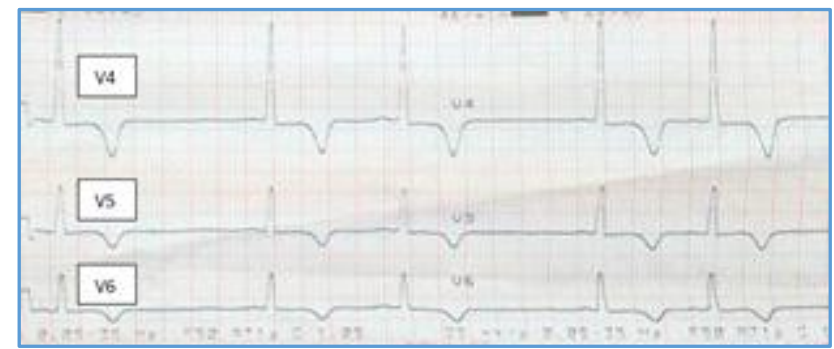

Fig. 2

Patient was treated with antiplatelets and antihypertensive drugs. Further hospital stay was uneventful.

\section{DISCUSSION}

Our case describes an unusual presentation of hypertrophic cardiomyopathy. Apical variant of HCM has been mainly reported in Japan with significantly much lesser prevalence in other populations. ${ }^{1-4} \mathrm{HCM}$ is transmitted as a Mendelian trait with an autosomal dominant pattern of inheritance. Mutations in two sarcomere genes, those encoding $\beta$-myosin heavy chain (MYH7) and myosin-binding protein C (MYBPC3) are by far the most common accounting for $70 \%$ of those successfully genotyped. 5 The apical HCM is frequently sporadic; however, a few families have been reported with autosomal dominant inheritance. ${ }^{6}$

Morphologically, AHCM is divided into 3 types: pure focal, pure diffuse and mixed, of which pure focal is most common. ${ }^{7}$ However, in clinical practice, this sub-classification is not widely accepted and its clinical relevance is unknown. Others have divided AHCM into two groups based on whether they had isolated asymmetric apical hypertrophy (pure AHCM) or had co-existent hypertrophy of the interventricular septum (mixed AHCM). ${ }^{8}$ Isolated hypertrophic obstructive cardiomyopathy of the right ventricle had been reported without any involvement of the interventricular septum or left ventricle.

The mean age of presentation of AHCM is $41.4 \pm 14.5$ years and is most commonly seen in males. ${ }^{4}$ About $54 \%$ of patients with AHCM are symptomatic and the most common presenting symptom is chest pain followed by palpitations, dyspnoea and syncope. ${ }^{8}$ AHCM may also manifest as morbid events such as atrial fibrillation, myocardial infarction, embolic events, ventricular fibrillation and congestive heart failure. Other complications of AHCM include apical aneurysm and cardiac arrest. Physical findings of and audible/palpable fourth heart sound and a new murmur are common. Our patient was relatively asymptomatic with no family history and no physical findings.

The most frequent ECG findings are negative T-waves in the precordial leads, which are found in $93 \%$ of patients followed by LV hypertrophy in $65 \%$ of patients. ${ }^{8}$ Negative Twaves with a depth $>10 \mathrm{~mm}$ are found in $47 \%$ of patients with AHCM. " "Giant T-wave inversion" (depth $>10 \mathrm{~mm}$ ) and loss of septal Q waves should raise strong suspicion of apical HCM and are found in $47 \%$ of cases. The ECG in our patient showed $\mathrm{LV}$ hypertrophy and negative T-waves.

Echocardiography has been universally accepted as the initial imaging modality in investigation of patients with apical HCM. ${ }^{8}$ The diagnostic criteria for apical hypertrophic cardiomyopathy included demonstration of asymmetric hypertrophy, confined predominantly to the apex with an apical wall thickness $\geq 15 \mathrm{~mm}$ and a ratio of maximal apical to posterior wall thickness $\geq 1.5$, based on echocardiography. ${ }^{9}$ In this case, asymmetric apical wall is $26 \mathrm{~mm}$ and its posterior wall is $4.2 \mathrm{~mm}$ and a ratio of maximal apical to posterior wall thickness 6.19, satisfying the diagnosis of apical left ventricular hypertrophic cardiomyopathy. The degree of thickness increases from base to apex resulting in a markedly diminished apical cavity and a spade-shaped left ventricular cavity suggesting apical left ventricular hypertrophic cardiomyopathy in the apical 4 chamber view of twodimensional echocardiographic image of this patient. Although, the initial diagnostic test for AHCM is most commonly TTE, the best diagnostic tool is considered to be cardiac MRI.

ACHM may mimic other conditions including apical cardiac tumours, LV apical thrombus, isolated ventricular noncompaction, Endomyocardial Fibrosis (EMF) and coronary artery disease. Chest pain in a patient with ACHM can be mistaken for ischaemia from coronary artery disease. ${ }^{10}$

The course of apical HCM is relatively benign. The overall mortality rate is $10.5 \%$. Some apical HCM patients may develop life-threatening complications such as sudden cardiac death, ${ }^{10}$ which is more commonly seen in asymmetric septal hypertrophy than apical $\mathrm{F}$ having syncopal episodes, arrhythmias, ventricular wall thickness $>30 \mathrm{~mm}$ or a family history of sudden death may benefit from ICD (Implantable Cardioverter Defibrillator) placement. Beta adrenergic blocking agents are the first line therapy for symptomatic patients. ${ }^{11}$ Since our patient was asymptomatic, he was managed conservatively with advice for regular followup.

\section{CONCLUSION}

Isolated apical left ventricular hypertrophic cardiomyopathy had been detected in a 55-year-old South-Indian male who is a hypertensive and chronic smoker; 2D echocardiography confirmed the rare finding of isolated hypertrophy of the left ventricular apex.

\section{REFERENCES}

1. Filho AFM, Castier MB, Lopes AS, et al. Is the apical hypertrophic cardiomyopathy seen in one population in Rio de Janeiro city similar to that found in the east? Arq Bras Cardiol 1997;69(2):117-123.

2. Sakamoto T, Tei C, Murayama M, et al. Giant T wave inversion as a manifestation of asymmetrical apical hypertrophy (AAH) of the left ventricle. Echocardiographic and ultrasono-cardiotomographic study. Jpn Heart J 1976;17(5):611-29.

3. Yamaguchi H, Nishiyama S, Nakanishi $S$, et al. Electrocardiographic, echocardiographic and ventriculographic characterization of hypertrophic nonobstructive cardiomyopathy. Eur Heart J 1983;4(Suppl F):105-119.

4. Eriksson MJ, Sonnenberg B, Woo A, et al. Long-term outcome in patients with apical hypertrophic cardiomyopathy. J Am Coll Cardiol 2002;39(4):638-645.

5. Maron BJ, Olivotto l. Hypertrophic cardiomyopathy. In: Mann DK, Zipes DR, Libby P, et al, eds. Braunwald's heart disease:a textbook of cardiovascular medicine. $10^{\text {th }}$ edn. New York, NY: McGraw-Hill 2001:p. 1574. 
6. Arad M, Penas-Lado M, Monserrat L, et al. Gene mutations in apical hypertrophic cardiomyopathy. Circulation 2005;112(8):2805-2811.

7. Choi EY, Rim SJ, Ha JW, et al. Phenotypic spectrum and clinical characteristics of apical hypertrophic cardiomyopathy: multicentre echo-doppler study. Cardiology 2008;110(1):53-61.

8. Mckenna WJ, Kleinebenne A, Nihoyannopoulos $\mathrm{P}$, et al. Echocardiographic measurement of right ventricular wall thickness in hypertrophic cardiomyopathy: relation to clinical and prognostic features. Journal of American College of Cardiology 1988;11(2):351-358.
9. Yusuf SW, Bathina JD, Banchs J, et al. Apical hypertrophic cardiomyopathy. World Journal of Cardiology 2011;3(7):256-259.

10. Yang HS, Song JK, Song JM, et al. Comparison of the clinical features of the apical hypertrophic cardiomyopathy versus asymmetric septal hypertrophy in Korea. Korean Journal of Internal Medicine 2005;20(2):111-115.

11. Sanidas E, Bonou M, Anastaadiadis G, et al. An atypical case of apical hypertrophic cardiomyopathy: absence of giant $\mathrm{T}$ waves in spite of extreme apical wall hypertrophy. Case Reports In Cardiology. Article ID 980971, 2015;2015:pgs. 3. http://dx.doi.org/10.1155/2015/980971. 